\title{
Surgical Management of Calcific Metamorphosis of Pulp: A Case Report
}

\author{
KULSUM U ${ }^{\mathrm{a}}$, FARZANA F ${ }^{\mathrm{b}}$
}

\begin{abstract}
:
A case is reported which states calcific metamorphosis of pulp in a mandibular left lateral incisor and concomitant pulp necrosis of both central incisors for a single trauma. There was a large periapical lesion associated with the teeth. Conventional endodontic treatment was performed on teeth with pulp necrosis, but the canal with calcific metamorphosis could not be negotiated with endodontic files. The periapical lesion was surgically removed and diagnosed as acute periapical abscess on histopathology. During the surgical procedure root apices of calcified tooth
\end{abstract}

Introduction:

Calcific metamorphosis is defined as a pulpal response to trauma that is characterized by deposition of hard tissue within the root canal space. ${ }^{1}$ Initially, calcification is a process involving the reduction in size of the intradental cavities as a result of hard-tissue formation by the cells of the vital pulp; it tends in complete calcification as a result of dentin deposition inside the tooth. ${ }^{2}$

The mechanism of hard tissue formation during calcific metamorphosis is characterized by an osteoid tissue that is produced by the odontoblasts at the periphery of the pulp space or can be produced by undifferentiated pulpal cells that undergo differentiation as a result of the traumatic injury. This results in a simultaneous deposition of a dentin-like tissue along the periphery of the pulp space and within the pulp space proper. These tissues can eventually fuse with one another, producing the radiographic appearance of a root canal space that has become rapidly and completely calcified. ${ }^{1}$

Calcifications of varying extent develop in teeth that have been subjected to luxation

a. Dr. Umme Kulsum, BDS, DDS, MS (Cons. Dentistry), Associate Professor, Department of Conservative Dentistry, Dhaka Dental College, Dhaka, Bangladesh.

b. Dr. Farhad Farzana, FCPS (Part II) trainee, Department of Conservative Dentistry \& Endodontics, Dhaka Dental College \& Hospital, Dhaka, Bangladesh

Address of Correspondence: Dr. Umme Kulsum, Associate Professor, Department of Conservative Dentistry, Dhaka Dental College, Dhaka, Bangladesh

Received: May 30, 2011

Accepted: June 30, 2011 as well as other teeth were removed and retrograde cavity was prepared and filled with glass ionomer cement i.e apicectomy was done.The bony defect was filled with calcium hydroxyappatite crystal. Six months later the teeth were asymptomatic and radiological follow-up showed gradual healing of the bony cavity.

Keywords: Retrograde filling, apicectomy, calcific metamorphosis of pulp, calcium hydroxyappatite crystal.

(Birdem Med J 2011; 1(1): 46-50)

trauma Pulpal necrosis occurs with some major delay in $20 \%$ of teeth with radiologically detectable calcifications. Calcifications have been observed in $2.3 \%$ of patients following

Le Fort I operations; according to other studies, the incidence may be as high as $30 \% .{ }^{2}$ Further causes that have been described include surgery-related changes in perfusion and in combined surgical and orthodontic treatment. Calcifications in the pulp chamber have also been observed following orthodontic treatment. ${ }^{2}$

The clinical picture of calcific metamorphosis has been described by Patterson and Mitchell as a tooth that is darker in hue than the adjacent teeth and exhibits a dark yellow color because of a decrease in translucency from a greater thickness of dentin under the enamel. ${ }^{1}$ Pulp testing ceases to have any diagnostic value once the calcification has reached an advanced stage. Radiograph alone can never be used as a basis for determining whether complete calcification has taken place; these teeth always require clinical verification. ${ }^{2}$

The radiographic appearance of calcific metamorphosis is partial or total obliteration of the pulp canal space with a normal periodontal ligament space and intact lamina dura. Complete radiographic obliteration of the root canal space, however, does not necessarily mean the absence of the pulp or canal space; in the majority of the cases there is a root canal space with pulpal tissue. ${ }^{1}$

Periapical lesions of endodontic origin are always manifestations of a disease that develops from the 
presence of microorganisms in the root canal system (or, in rare cases, in the periapical region). Healing can take place only if these bacteria are removed as completely as possible. Therefore, root canal treatment is strongly indicated in a tooth with a partially (apparently) calcified root canal system and apical periodontitis. ${ }^{2}$

Calcifications completely or partially block and obscure the access into the root canal systems and can hamper preparation, disinfection and obturation. Searching for calcified root canal systems carries an increased risk of perforation. However, if all attempts still fail to result in complete exposure and instrumentation of the root canal system, the clinician should consider root end resection or apicectomy, hemisection or extraction. ${ }^{2}$

The purpose of this article is to describe a clinical case of calcific metamorphosis of pulp associated with acute periapical abscess treated by apicectomy and retrogradefilling with glass ionomer cement and filling of bony cavity with hydroxyappatite crystal.

\section{Case Report}

A 23 year-old male, named Md. Monirul Islam was referred to the Department of Conservative Dentistry \& Endodontics, Dhaka Dental College \& Hospital, with pain and swelling in his mandibular left lateral incisor. The patient described recent severe pain over 3 days, but no previous history or any signs or symptoms. He gave a history of trauma about 15 years back. The patient could not recollect about the treatment he received at that time. The medical history was noncontributory. Yellow discoloration on mandibular left central incisor was noticed (Fig-1). Both central incisors and left lateral incisors were sensitive to percussion, but failed to respond to pulp sensitivity testing. The labial gingiva was tender on palpation. A periapical radiograph revealed a large radiolucent area of $(13 \times 8) \mathrm{mm}^{2}$ involving apices of the mandibular central incisors and left lateral incisor. Left central incisor showed open apex (not divergent) and the left lateral incisor was calcified (Fig-2). A clinical diagnosis of calcific metamorphosis of pulp in mandibular left lateral incisor, pulp necrosis of mandibular central incisors with chronic periapical abscess was established. Taking into account the canal with calcific metamorphosis and open apices (not divergent) and the periapical radioluscency, the first step of treatment was root canal treatment and the need for apicectomy followed by retrograde filling was in consideration.

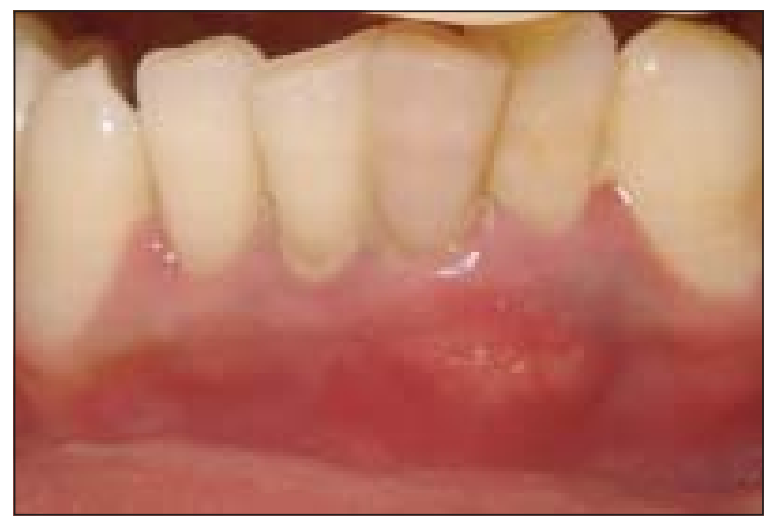

Fig.-1: Periapical abscess in mandibular incisors

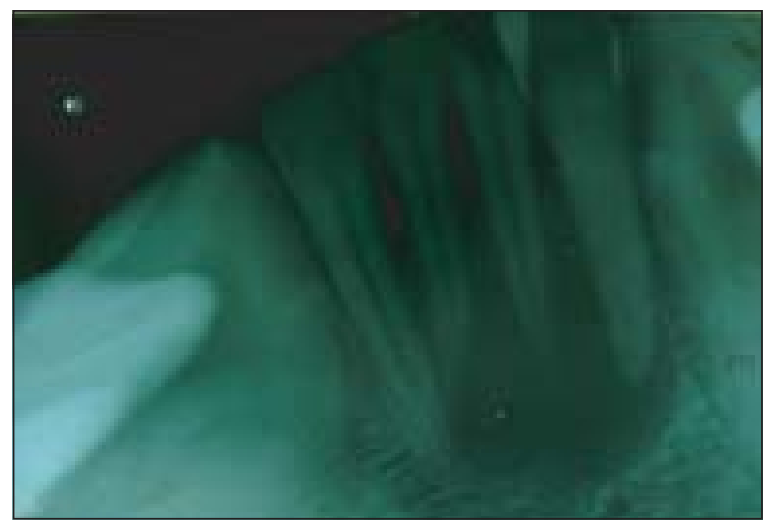

Fig.-2: Preoperative radiograph showing calcification of mandibular left lateral incisor

Following isolation of the teeth pus was drained through access cavity of both mandibular central incisors. A radiograph was obtained with files inserted in the root canals to establish working length. Both canals were debrided thoroughly and prepared by standardized technique to a size 35 file. Copious irrigation with $1 \%$ sodium hypochlorite solution was carried out throughout the procedure. After drying the root canals with paper points, calcium hydroxide was applied and cavity was temporarily sealed with zinc oxide eugenol cement.

An access opening was made on the left lateral incisor tooth at the same visit but the root canal could not be negotiated with an endodontic file and EDTA as the canal was calcified. Then decision was made for combined nonsurgical and surgical endodontic treatment.

One week later, the right central incisor tooth was sealed with gutta-percha point and zinc-oxide eugenol cement 
using lateral condensation technique, followed by coronal sealing. A postoperative radiograph was obtained (Fig-3). The left central incisor was decided for through and through obturation during surgical procedure because of presence of pus as well as open apex.

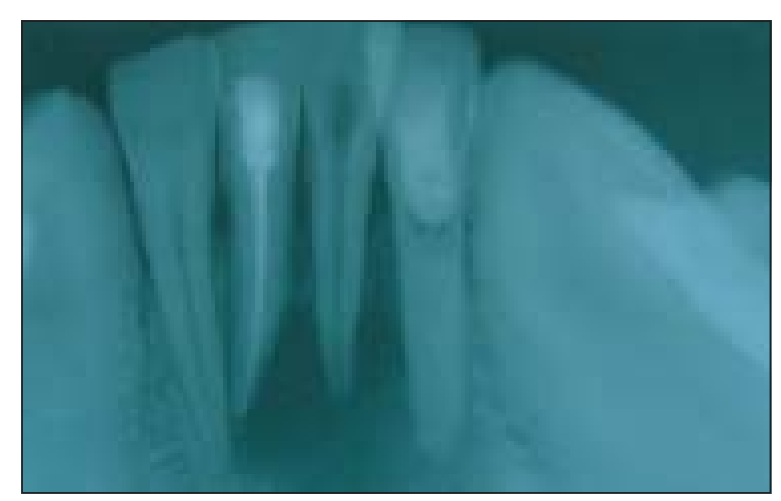

Fig.-3: Obturation of mandibular right Central incisor.

After 7 days, the patient returned and apical surgery was performed to remove a portion of the with undebrided space and to retroseal the canal. The surgical intervention consisted of apical curettage, apicectomy, root-end preparation and retrofilling.

An intrasulcular incision along with two vertical incisions at each end was made under local anaesthesia, a full thickness flap was retracted, and bone removed to gain access to the lesion and to the apical third of the root. The granulation tissue was removed with the help of surgical curette (Fig-4) and sent for histopathological examination (Fig-5). The lower left central incisor tooth which was with open apices was sealed through and

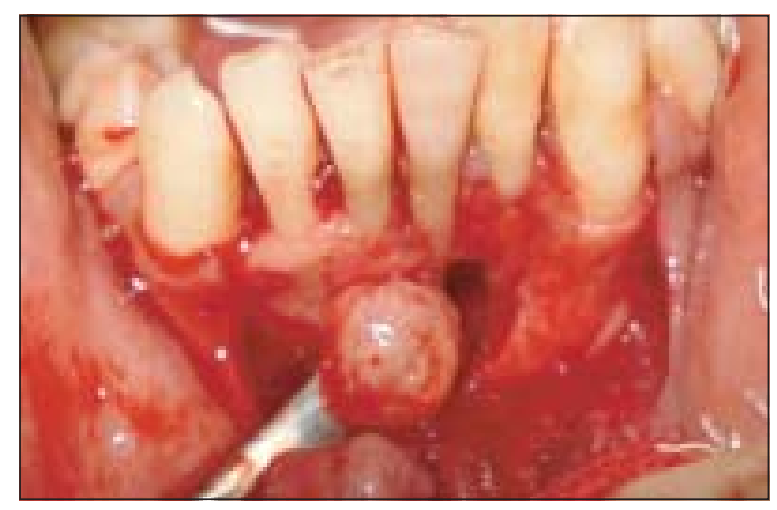

Fig.-4 : Removal of abscess wall with curette

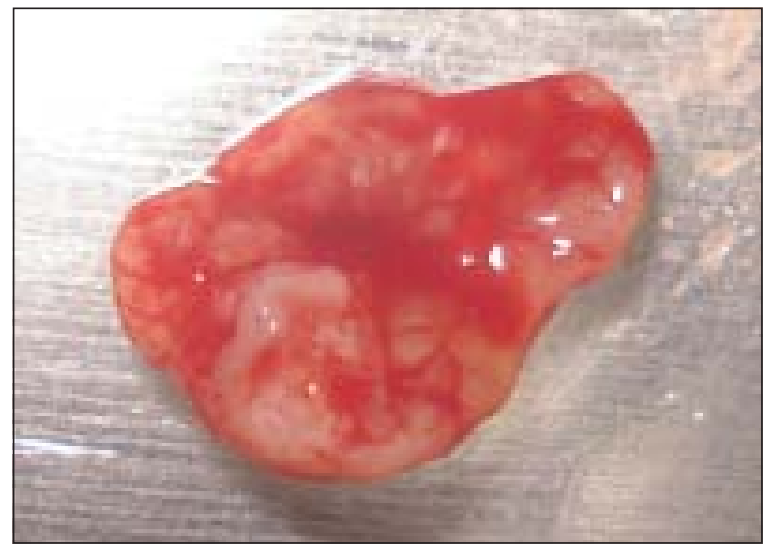

Fig.-5: Tissue for Histopathological examination.

through with gutta-percha point and zinc oxide eugenol sealer followed by coronal sealing. The resection involved the apical $3 \mathrm{~mm}$ of the root on both teeth i.e. on calcified canal and open apex, with a bevel of 0 degree angle to the long axis of the tooth, using a high speed diamond fissure bur, followed by finishing with a diamond finishing bur and irrigation with sterile saline.

The root-end was prepared with a round diamond bur 3 $\mathrm{mm}$ into root dentine to receive the glass ionomer filling material. The cavity was dried and glass ionomer filling was prepared and placed on to the root-end cavity. The bony cavity was cleaned with normal saline and filled with calcium hydroxyappatite crystal (Fig-6). Sutures were used to close and healing and healing period was uneventful.

Histopathological examination showed fibro edematous infiltration with inflammatory cells suggestive of wall of an abscess.

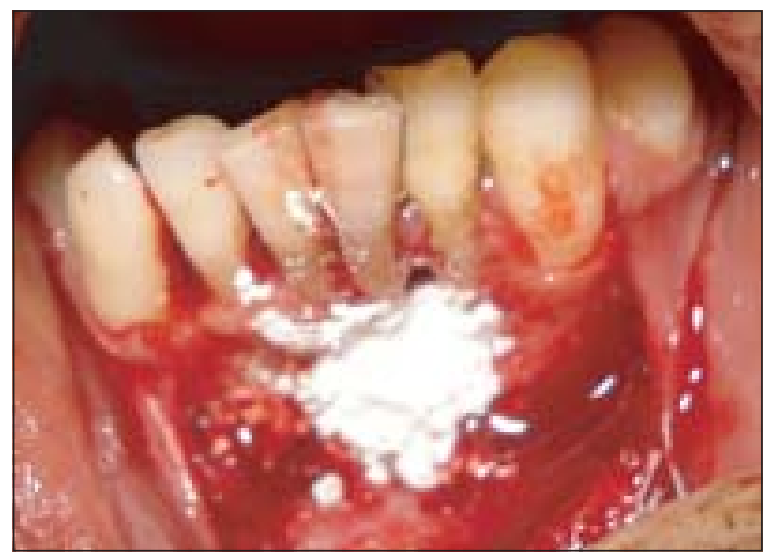

Fig.-6: Hydroxyappatic crystal in the bony cavity. 


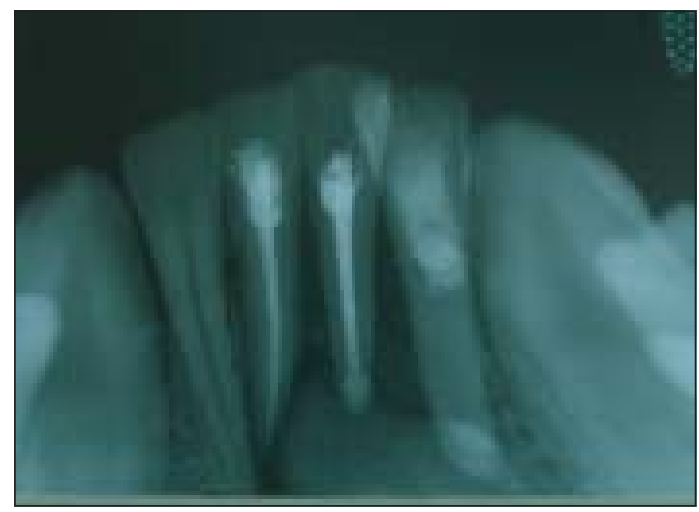

Fig.-7: Radiograph immediately after Apicectomy showing retrofilling.

At 3-month and 6 months follow-up examinations, the patient was asymptomatic and radiographic evidence of gradual healing was confirmed by a decrease in the size of the periapical radiolucency.

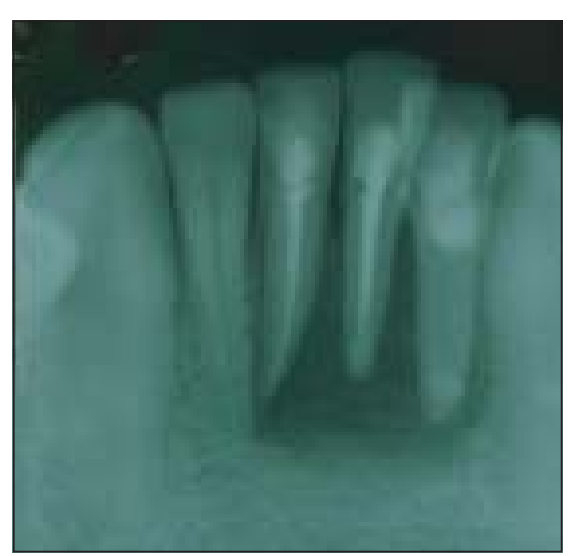

Fig.-8: Three month follow-up radiograph after apicectomy

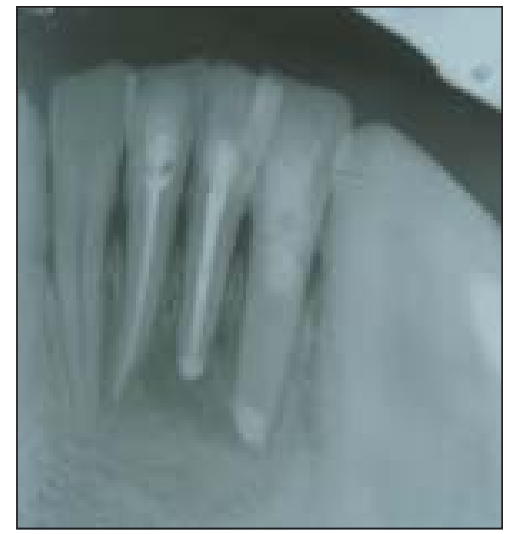

Fig.-9: Six month follow-up radiograph after apicectomy radiograph showing gradual healing.

\section{Discussion}

Depending on its severity, injury to the oral cavity can involve all dental tissues ${ }^{3}$. Biological consequences of traumatic luxation injury include pulp necrosis, calcification and root resorption either internal and/ or external along with bone resorption ${ }^{4}$. The cause of pulp pathology is infectious products from an infected pulp space or from the periapical area. Microorganism that colonize these areas release their product into the periapical tissue and causes a lesion in the bone. The severity of destruction is dependent on the amount of products as well as the resistance of the host. The inflammatory development might be acute, and leading to a periapical abscess or chronic with sign of a periapical granuloma or cyst ${ }^{5}$. The reported case showed almost all biological consequences of traumatic injury.

Most of the recent literature indicates that endodontic treatment is unnecessary unless the tooth is symptomatic or there is radiographic evidence of pulp necrosis and infection i.e., periapical radiolucency ${ }^{2}$. Signs of pulp necrosis and infection may be seen in a small percentage of calcified canals particularly in which the pulp appears almost totally calcified and in teeth with complete root formation. ${ }^{6}$

Assessment of the status of the pulp was difficult since these teeth do not usually respond to thermal sensibility testing. Most, however, do respond to electrical stimulus and therefore the electrical pulp sensibility testing is the desirable method for assessing the status of the pulp in calcified canals. The reported case was nonresponsive to thermal sensibility test; electrical sensibility could not be performed because of economical consideration ${ }^{6}$. In the present case, radiographic complete calcific metamorphosis of pulp in a mandibular lateral incisor was associated with a large periapical lesion with concomitant pulp necrosis of both central incisors and thus endodontic treatment was inevitable.

Pulp chamber was flooded with $1 \%$ sodium hypochlorite. Canal with calcific metamorphosis was instrumented with fine file, though radiographic interpretation suggested for complete blockage. Ethylenediamine tetraacetic acid (EDTA) solution was used to assist in canal penetration. Surgical Operating Microscope (SOM) for visualization and magnification, 
Ultrasonic (US) tip ${ }^{7}$ or Laser light ${ }^{8}$ for locating and negotiating calcified canal was not chosen because of financial consideration.

Symptomatic teeth that exhibit complete calcific metamorphosis radiographically or in which the canals cannot be negotiated must be treated with periradicular surgery. ${ }^{1}$

In the present case, all attempts with available facilities failed in negotiation and instrumentation of the calcified canal and decided for apicectomy followed by retrograde filling. Apicectomy and retro-preparation was performed with conventional method.

Laser-powered apicectomy and ultrasonic retropreparation was not chosen because of non-availability and financial consideration.

Periapical surgery is successful in $25.0-99.0 \%$ of cases, and success is influenced by many factors including the tooth involved, surgical procedure, complex anatomy of the root canal, quality of root canal filling, apical repair and the length of follow-up. ${ }^{9,10,11}$ In this case, 3 $\mathrm{mm}$ apical resection was performed with 0 bevel. According to Cohen et al. the length of root for resection depends upon the frequency of lateral canals and apical ramifications at the root-end. They found that when 3 mm of apex is resected, the lateral canals are reduced by 93 percent and apical ramifications decreased by 98 per cent. Whereas a root resection of $3 \mathrm{~mm}$ at a 0 degree bevel angle eliminates most of the anatomic features that are possible cause of failure. ${ }^{1}$

In the present case, retrograde filling was undertaken with glass-ionomer cement, which has been shown to have good apical sealing properties, availability and is less expensive. Though this cement is more sensitive to contamination with saliva and blood unlike expensive MTA, it exhibits satisfactory periapical healing after apical surgery ${ }^{12}$.

The bony cavity was filled with calcium hydroxyappatite crystal, a non-resorbable alloplastic material as studies showed reduction of the osseous defects greater in hydroxyappatite than curettage only ${ }^{13}$.

\section{Conclusion:}

Because of the calcific metamorphosis of pulp and an acute periapical abscess with concomitant pulp necrosis, combined nonsurgical and surgical endodontic therapy was indicated in this case. Follow-up radiograph over 6 months showed marked reduction of size of the radiolucency and thereby healing.(Fig:8-9)

\section{Referrences:}

1. Garg N, Garg A.Pulp and Periradicular tissue.In:Garg N, Garg A. editors. Textbook of Endodontics $1^{\text {st }}$ edition .New Delhi:Jitendar P Vij,..2007:7-21

2. Michael Hulsmann, Claudia Barthel. Problem in gaining access to the root canal system. In:Problems in Endodontics. $4^{\text {th }}$ edition.Germany:Quintessence International,1997;8:145-272.

3. Trope M, Chivian N. Traumatic injuries. In:Cohen S.burms RC eds.Pathways of the pulp, $6^{\text {th }}$ ed, . Mosby, St Louis.1994; 16; 436-85.

4. Trope M, Lucia Blanco, Noah Chivian, and Asgeir Sigurdsson .The Role of Endodontics after Dental Traumatic Injuries. In:Cohen S,Kenneth M eds.Pathways of the Pulp. $9^{\text {th }}$ edition. Mosby, St Louis.1994; 17; 436-85.

5. Prodeep M,Prosant MNikhil B,Nitika B.Principles of management of calcified canals.Indian J Dent Sc 2010;2(5):35

6. Moule AJ, Moule CA, The endodontic management of traumatized permanent anterior teeth: a review. Australian Dental J (Suppl.1); 2007; 52: (1 Supple): S 122-73.

7. Richard Mounce. Locating and Managing Calcified Canals: Optimal Strategies. Dental News 2007; 14: 4.-7

8. Selden S.The role of dental operating microscope in improved nonsurgical treatment of calcified canals.Oral Surg Oral Med Oral Pathol 1989;68:93-8.

9. Molven O, Halse A, Grung B, Surgical management of endodontic failures: indications and treatment results. Int Dent J 2007; 41:33-42.

10. Grung B, Molven O, Halse A, Periapical surgery in a Norwegian country hospital: follow-up findings of 477 teeth. J Endod 1990; 16: 411-17.

11. Testori T, Capelli M, Milani S, Weinstein RL, Success and failure of radicular surgery: a longitudinal retrosprective analysis. Oral Surg Oral Med Oral Radiol Endod 1999; 87: 493-98.

12. Jesslen P, Zetterqvist L, Heimdahl A, Longterm result of amalgam versus glass ionomer cement as apical sealer after apicectomy. Oral Pathol Oral Radiol Endod 1995; 79: 101103.

13. Thorkild Karring, Jan Lindhe, Pierpaolo Cortellini. Regenerative periodontal therapy.InLindhe J,Karring T,eds. Clinical Periodontology and Implant Dentistry. $3^{\text {rd }}$ edition ,. Lange .London. 1997; 20: 597-46. 